\title{
Fabrication of Photonic Crystal Structures on Flexible Organic Light-Emitting Diodes by Using Nano-Imprint and PDMS Mold
}

\author{
Ting-Lin $\mathrm{HO}^{\mathrm{a}}$, Quang-Cherng HSU ${ }^{\mathrm{b}}$, Yu-Liang $\mathrm{CHEN}^{\mathrm{c}}$ and Bao-Hsin LIU ${ }^{\mathrm{d}}$ \\ Department of Mechanical Engineering, National Kaohsiung University of Applied Sciences \\ 415 Chien-Kung Road, Kaohsiung 80778, Taiwan. \\ a1097303139@cc.kuas.edu.tw1, b hsuqc@kuas.edu.tw, \\ c frankchen2341@gmail.com, ${ }^{\mathrm{d}}$ hsin97891151@gmail.com
}

\begin{abstract}
In this paper, nanoimprint lithography was used to create a photonic crystals structure film in organic light-emitting diode (OLED) component, and then compare the efficiency of components whether with nanostructure or not. By using two different kinds of mold, such as silicon mold and PDMS mold, the nano structures in PMMA (molecular weight of $350 \mathrm{~K})$ were fabricated. Nanostructures in period of $403.53 \mathrm{~nm}$ with silicon mold and nano structures in period of $385.64 \mathrm{~nm}$ with PDMS mold as photonic crystal films were fabricated and were integrated into OLED. In experimental results, the OLED without photonic crystal films (with packing) behaves $193.3 \mathrm{~cd} / \mathrm{m}^{2}$ for luminous intensity, $3.481 \mathrm{~cd} / \mathrm{A}$ for lightening efficiency $\left(\eta_{L}\right)$ and $0.781 \mathrm{~lm} / \mathrm{W}$ for lightening power $\left(\eta_{P}\right)$ where $\mathrm{V}$ is $14 \mathrm{~V}$ and I is $5.5537 \mathrm{~mA}$; the OLED with photonic crystal films (with packing) behaves $241.6 \mathrm{~cd} / \mathrm{m}^{2}$ for luminous intensity, $4.173 \mathrm{~cd} / \mathrm{A}$ for lightening efficiency $\left(\eta_{L}\right)$ and $0.936 \mathrm{~lm} / \mathrm{W}$ for lightening power $\left(\eta_{P}\right)$ where voltage of $14 \mathrm{~V}$ and current (I) of $5.7891 \mathrm{~mA}$, which shows that the latter perform is well.
\end{abstract}

\section{Introduction}

OLED is often to combine with nano/micro structure to enhance light extraction whose common methods are as follows: application scattering layer on the OLED surface [1], to cover an ordered microlens arrays [2], using anodic aluminum oxide (AAO) films [3], and applied photonic crystal technology [4-7]. In the technology of photonic crystal, usually use nanoimprint lithography (NIL) to fabricate. The nanoimprint lithography which is a hot embossing lithography is proposed by Stephen Y. Chou in 1995 [8]. Now, several NIL have been developed like in the following example: UV-NIL [6], soft lithography [9], a combined nanoimprint and photolithography (CNP) patterning technique [10, 11], Laser-Assister Direct Imprint (LADI) process [12], and reversal imprinting [13]. In the stand NIL, the transferred pattern will be fail (or broken) due to the pattern size is too small or imprinted stress is too big, etc. and then a reversal imprinting is developed.

* Corresponding author: 1097303139@cc.kuas.edu.tw 
This technology is to coat a liquid polymer material on the hard mold, and then the coating surface cover and combine on the substrate, through elevated temperature and pressure, the pattern of hard mold has transferred on the substrate. Therefore, the glass transition temperature $\left(\mathrm{T}_{\mathrm{g}}\right)$ of the substrate and PMMA, and the surface energy of substrate with coating (PMMA liquid) surface are important. In this paper, the PDMS was an adhesive layer between the PMMA and substrate, and used reversal imprinting to fabricate photonic crystal on the OLED (refractive index, PMMA=1.43; PDMS=1.49; PET=1.6; ITO=1.85). Two different material molds that were PDMA mold and Si mold were used in the photonic crystal fabrication. The PMMA mold was fabricated from Si mold imprinting; and then discussed transferred effects of soft mold structure in NIL. Finally, in luminous efficiency the photonic crystals of same periodic and different structure were compared.

\section{Experiments and Methods}

In this paper, two kinds of materials used in stamps; one is silicon and another is polydimethylsiloxane (PDMS). The stamp with holes or columns pattern of $200 \mathrm{~nm}$ in diameter, nanostructures in period of $403.53 \mathrm{~nm}$ with silicon mold and nano structures in period of $385.64 \mathrm{~nm}$ with PDMS mold in height covering $17 \mathrm{~mm}^{2}$ areas were built, and there are two array types, where one is hexagonal array of holes and other is square array of columns, as shown in Fig. 1 and Table 1.

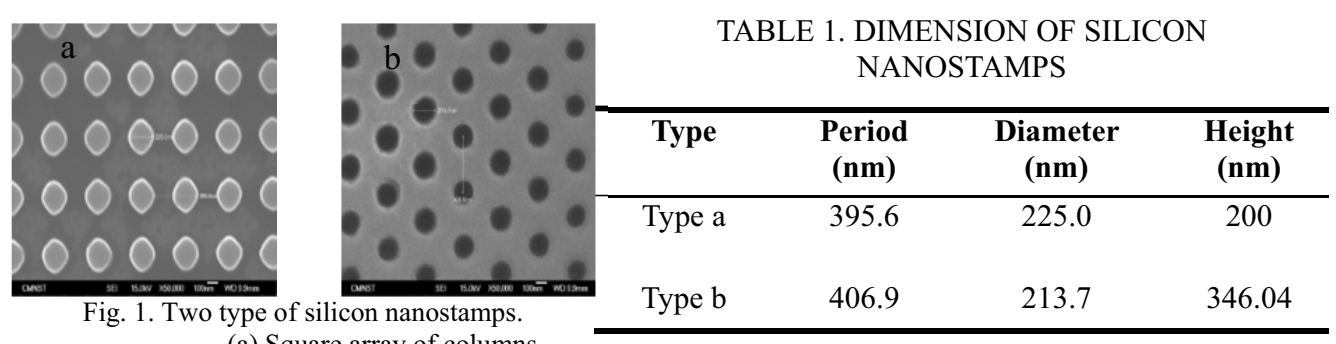

(a) Square array of columns.

(b) Hexagonal array of holes.

The experimental processes consist of three main parts: (1) photolithography of Indium Tin Oxide (ITO) film, (2) Photonic crystal thin film, (3) Photonic crystal combines organic light-emitting diodes (OLED), in Fig. 2. And then, One of the process of (2) Photonic crystal thin film, contains two kinds of materials, the original silicon stamp and transfer soft stamp of PDMS. The PDMS stamp was used PDMS (SYLGARD184, 10:1 ratio of base and curing agent) to form the photonic crystal nanostructure. First, PDMS solution poured onto a silicon stamp, and then it was baked (temperature of $180^{\circ} \mathrm{C}$, in 1 hour) in an oven, finally, the PDMS stamp was stripped from silicon stamp.

ITO film photolithography process. In photolithography process, a positive photoresist of AZ-4620 used into make the anode in polyethylene terephthalate (PET) /indium-tin oxide (ITO) structure. As shown in Fig. 2, step 1a to 1d, the photolithography processes contain with spin coating of photoresist, soft baking, developing, cleaning, and hard baking were used. The process parameters are shown in Table 2. 


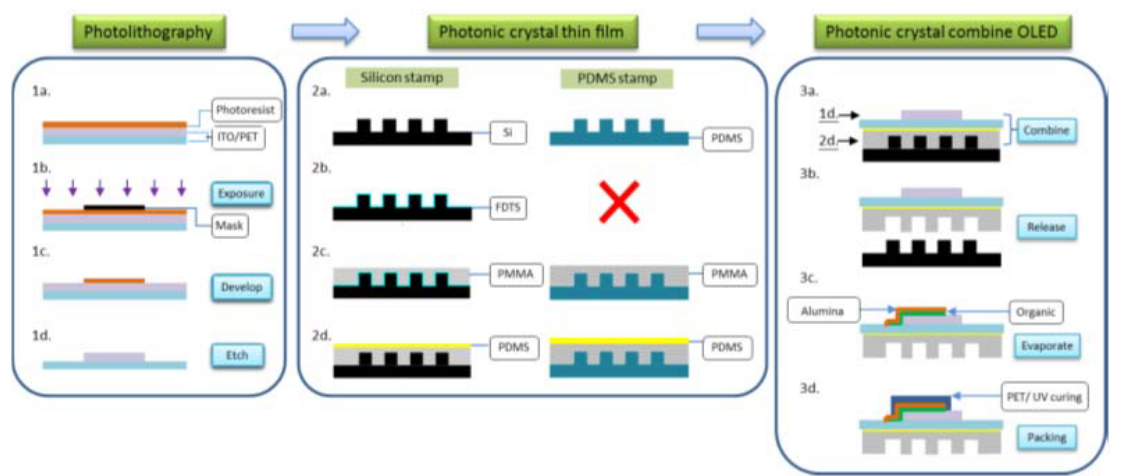

Fig. 2. Experimental process diagram for OLED with nanopatterned photonic crystal.

\section{Photonic crystal thin film.}

Anti-adhesive. In nanoimprint process, the silicon stamp must be decrease the adhesion between the silicon stamp and PMMA layer. Using self-assembled monolayers (SAMS) of $1 \mathrm{H}, 1 \mathrm{H}, 2 \mathrm{H}, 2 \mathrm{H}$ - perfluorodecyltrichlorosilane (FDTS) were coated on the surface of silicon stamp. Fig. 3 shows the contact angle between stamp and water.

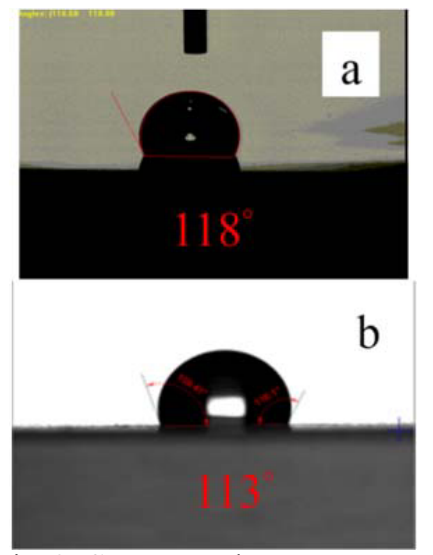

TABLE 2. PROCESS PARAMETERS FOR PHOTOLITHOGRAPHY.

\begin{tabular}{l|l}
\hline Step & Process parameters \\
\hline Speed and time for spin & $1000 \mathrm{rpm}, 15 \mathrm{sec} ; 2000 \mathrm{rpm}$, \\
coating & $30 \mathrm{sec}$ \\
Soft-baking & $105^{\circ} \mathrm{C}, 90 \mathrm{sec}$ \\
Cooling time & $2 \mathrm{~min}$ \\
Exposure time & $34 \mathrm{sec}$ \\
Development time & $3 \mathrm{~min}$ \\
\hline
\end{tabular}

Fig. 3. Contact angle measurement

of

(a) silicon stamp with

FDTS and

(b) PDMS stamp without

FDTS.

Photonic crystal of PMMA. The PMMA (molecular weight of 350k) were poured on the top of a stamp (silicon or PDMS stamp). After 20 minutes, they were moved into vacuum chamber to remove the residual air between stamp and PMMA. Then, PDMS was spin-coated on the top of PMMA where PET/ITO structure was placed. Fig. 4 and Table 3 show nanostructures and parameters of diameter. 
a

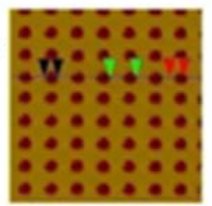

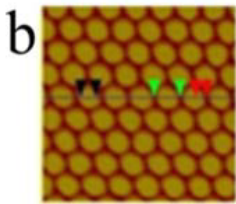

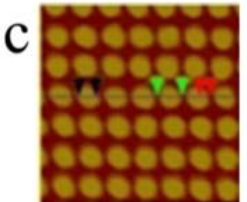

$\mathrm{d}$

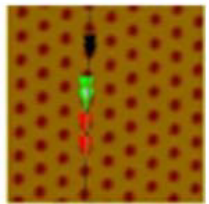

Fig 4. AFM images of nanoimprint results. The patterns (a, b) are Si stamp imprinted structures, and (c, d) are PDMS stamp imprinted structures.

TABLE 3. AFM MEASUREMENT STRUCTURES OF THE PMMA PHOTONIC CRYSTAL. (UNIT: NM)

\begin{tabular}{|c|c|c|c|c|}
\hline \multicolumn{2}{|c|}{ Type } & Period & Diameter & Height \\
\hline \multirow{2}{*}{ Si stamp imprinted } & $\mathrm{a}$ & 406.35 & 204.17 & 203.75 \\
\cline { 2 - 5 } & $\mathrm{b}$ & 403.53 & 210.47 & 202.68 \\
\hline \multirow{2}{*}{$\begin{array}{c}\text { PDMS stamp } \\
\text { imprinted }\end{array}$} & $\mathrm{c}$ & 389.53 & 185.47 & 188.68 \\
\cline { 2 - 5 } & $\mathrm{d}$ & 385.64 & 211.47 & 187.53 \\
\hline
\end{tabular}

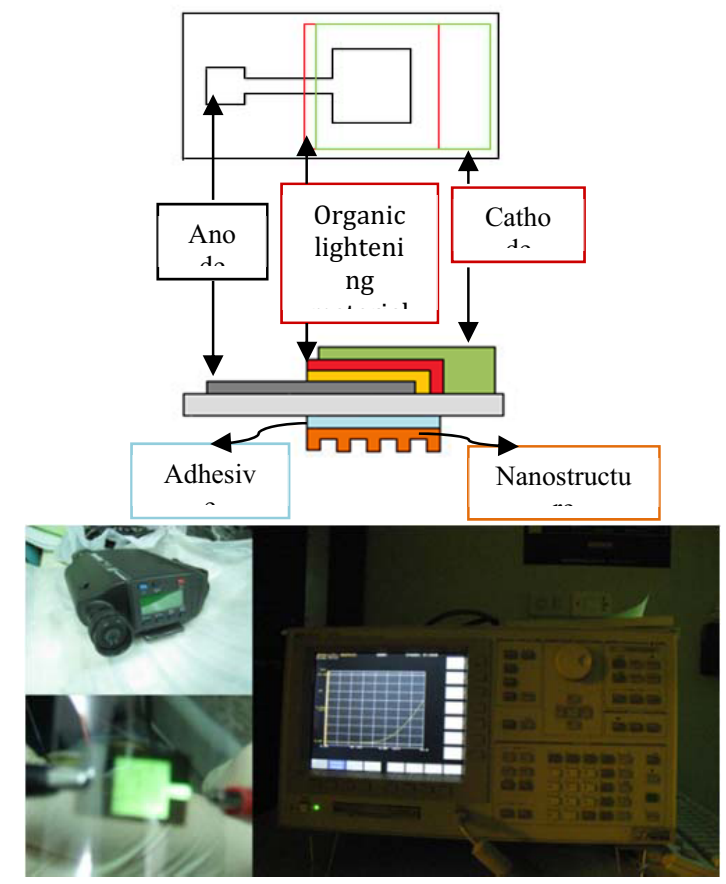

Fig. 5. Layered structure of a photonic crystal OLED.

Fig. 6. Semiconductor analyzer and photometer.

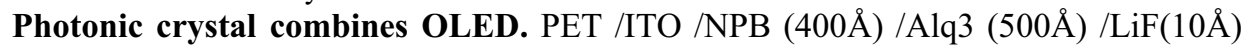
$/ \mathrm{Al}(1500 \AA) / \mathrm{X}$ is the layer arrangement for the current study, as shown in Fig. 5. The evaporation chamber was vacuumed until $8 \times 10$-6torr, NPB and Alq 3 were vaporized and deposited at 120 and $150^{\circ} \mathrm{C}$, respectively, under the coating rate of $0.5-1 \AA / \mathrm{sec}$. $\operatorname{LiF}(5 \AA)$ was an electron transmission layer. The cathode was $\mathrm{Al}$ which was vaporized by E-beam 
vaporizing machine with the coating speed of $2.5 \AA / \mathrm{sec}$. A PET film was covered on top of the whole OLED whose boundary was sealed by UV glue, where X means with or without a PET thin film. The fabricated OLED with nano-patterned photonic crystal was measured by semiconductor analyzer and photometer as shows in Fig. 6.

\section{Results and discussion}

Nanoimprint. The results show that the shape effect of nanostructure in the transfer process, nanoholes, and the nanocolumns structure caused different results of dimension, as shown in Fig. 7 and 8.

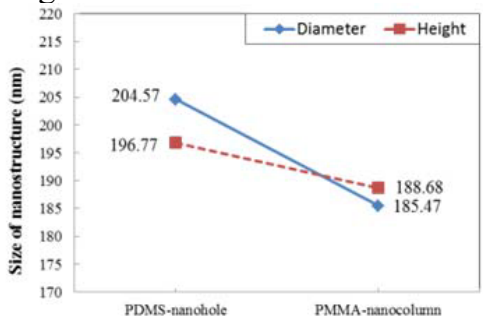

Fig. 7. The imprinted results of the nanohole PDMS stamp.

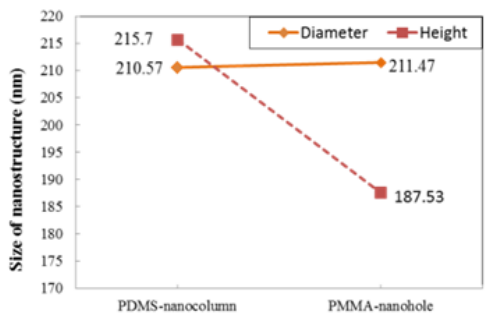

Fig. 8. The imprinted results of the nanocolumn PDMS stamp.

Shape effect. Because the PDMS stamp is soft material then the deformation of a stamp by normal stress, consider the graphic representation in Fig. 9. The diameter became smaller for nanoholes structure which received normal stress effect; as a result, the diameter is decreasing $(-19.1 \mathrm{~nm})$. The diameter became bigger for nanocolumns structure which received normal stress effect; as a result, the diameter is increasing $(0.9 \mathrm{~nm})$. Moreover, the height became lower, the nanocolumns $(-28.7 \mathrm{~nm})$ was greater than the nanoholes transfer pattern $(-8.09 \mathrm{~nm})$.

a
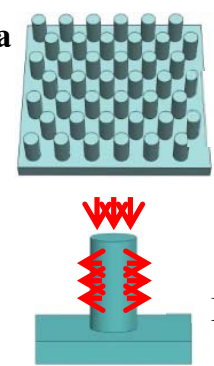

Element
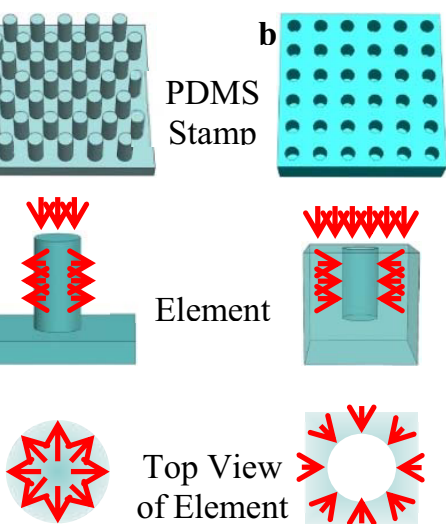

Top View of Element $1 \wedge \Gamma$

Fig. 9. Different effects of the two types nanoimprint structure. (a) Nanocolumns effect.

(b) Nanoholes effect.
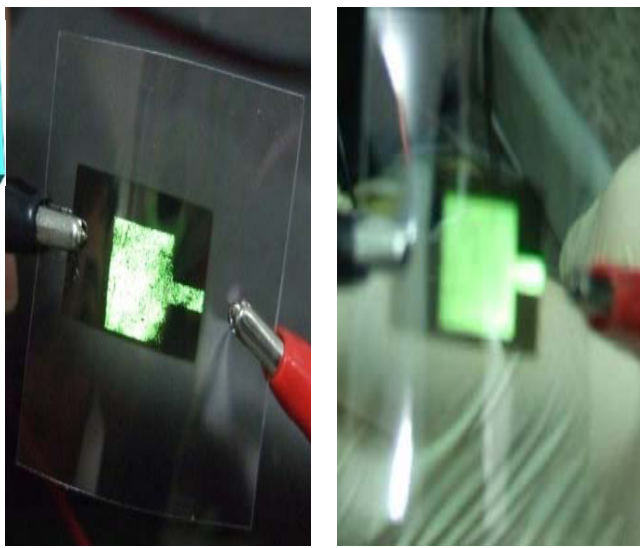

Fig. 10. OLED testing,

Left: without PET packing

Right: with PET packing.

Comparison between packing and no packing. In order to obtain the effect of PET thin film packing on OLED performance, two cases were tested. The OLED structure is

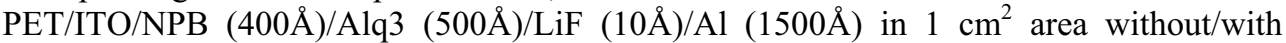
packing and no photonic crystal. Table 4 and Fig. 10 to 11 shown the experimental results on driving voltage of $15.5 \mathrm{~V}$ and current of $3.97 \mathrm{~mA}$ (without packing), $14 \mathrm{~V}$ and current of 5.55 
mA (with packing). The OLED with packing was better than without packing. Lower luminous efficiency due to chip which oxidized was without packing.

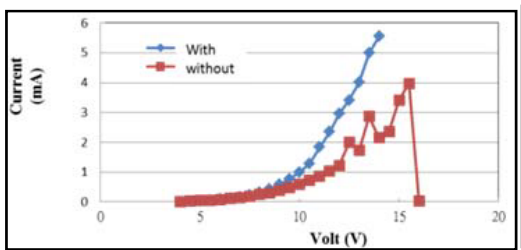

Fig. 11. Comparing packing effect. (a) I-V curves. (b) L-V curves.

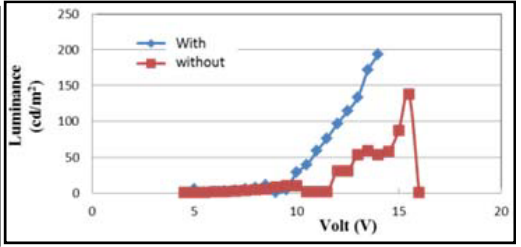

TABLE 4. OLED PERFORMANCE WITH PACKING.

\begin{tabular}{l|lll}
\hline Packing & $\begin{array}{l}\text { Luminous } \\
\text { intensity } \\
\left(\mathrm{cd} / \mathrm{m}^{2}\right)\end{array}$ & $\begin{array}{l}\text { Lightening } \\
\text { efficiency } \eta_{\mathrm{L}} \\
(\mathrm{cd} / \mathrm{A})\end{array}$ & $\begin{array}{l}\text { Lightening } \\
\text { power } \\
\eta_{\mathrm{p}}(\mathrm{m} / \mathrm{W})\end{array}$ \\
\hline Without & 137.8 & 3.4707 & 0.7035 \\
With & 193.3 & 3.4806 & 0.781 \\
\hline
\end{tabular}

Four different types of photonic crystal layer and packing. OLED structure of

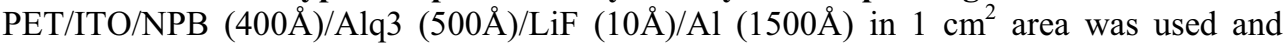
packing. Four different photonic crystals such as the following: square array of nanoholes, hexagonal array of nanocolumns, square array of nanocolumns and hexagonal array of nanoholes. Table 5 shows the lightening measured results. In this study, compared OLED with no photonic crystal, the square array of nanoholes is the best nanostructure on the photonic crystal OLED as shown in Fig. 12.

TABLE 5. MEASUREMENT RESULTS OF fIVE OLED THIN fiLM.

\begin{tabular}{|c|c|c|c|}
\hline OLED thin film & $\begin{array}{c}\text { Luminous intensity } \\
\left(\mathrm{cd} / \mathrm{m}^{2}\right)\end{array}$ & $\begin{array}{c}\text { Lightening } \\
\text { efficiency } \eta_{\mathrm{L}}(\mathrm{cd} / \mathrm{A})\end{array}$ & $\begin{array}{c}\text { Lightening power } \eta_{\mathrm{p}} \\
(\mathrm{lm} / \mathrm{W})\end{array}$ \\
\hline Without photonic crystal & 193.3 & 3.4806 & 0.781 \\
\hline Nanoholes & 241.56 & 4.1726 & 0.9363 \\
\hline Nanocolumns & 222.43 & 4.0431 & 0.9073 \\
\hline Nanoholes (soft stamp) & 212.53 & 3.8038 & 0.8536 \\
\hline Nanocolumns (soft stamp) & 203.37 & 3.7099 & 0.8325 \\
\hline
\end{tabular}

\section{Conclusions}

In this research, anti-adhesive is a PDMS property, and then it cannot coat FDTS. However, the transferred pattern size is changed due to nano-structure deformation of the stamp by normal stress. Two different nanostructures size change are discussed under nanoimprinting. A nanocolumns stamp embossing can cause transferred nanoholes of diameter reaming and height decreasing. Other nanoholes stamp embossing can cause transferred nanocolumns diameter decreasing and height decreasing. Furthermore, the nanocolumns height change is bigger than nanoholes.

In the OLED packing, the OLED without packing behaves $15.5 \mathrm{~V}$ for $\mathrm{Voc}, 3.9703 \mathrm{~mA}$ for Isc, $137.8 \mathrm{~cd} / \mathrm{m}^{2}$ for Luminous, $3.4707 \mathrm{~cd} / \mathrm{A}$ for lightening efficiency $\left(\eta_{\mathrm{L}}\right)$ and 0.7035 $\mathrm{lm} / \mathrm{W}$ for lightening power $\left(\eta_{\mathrm{P}}\right)$; the OLED with packing behaves $14 \mathrm{~V}$ for $\mathrm{Voc}, 5.5537 \mathrm{~mA}$ 
for Isc, $193.3 \mathrm{~cd} / \mathrm{m} 2$ for Luminous, $3.4806 \mathrm{~cd} / \mathrm{A}$ for lightening efficiency $\left(\eta_{\mathrm{L}}\right)$ and 0.7810378 $\mathrm{lm} / \mathrm{W}$ for lightening power $\left(\eta_{\mathrm{P}}\right)$, which show the OLED packing can enhance lightening performs. Four different nanostructures were fabricated to obtain the lightening results for each was in a $1 \mathrm{~cm}^{2}$ OLED surface. The best OLED structure is with the square array of nanoholes photonic crystal films behaves $14 \mathrm{~V}$ for Voc, $5.7891 \mathrm{~mA}$ for Isc, $241.56 \mathrm{~cd} / \mathrm{m}^{2}$ for Luminous, $4.1726 \mathrm{~cd} / \mathrm{A}$ for lightening efficiency $\left(\eta_{\mathrm{L}}\right)$ and $0.9363 \mathrm{~lm} / \mathrm{W}$ for lightening power $\left(\eta_{\mathrm{P}}\right)$.In nanostructures, the comparison sequence of lightening degree: 1. Square array of nanoholes. 2. Hexagonal array of nanocolumns. 3. Hexagonal array of nanoholes. 4. Square array of nanocolumns. And then, the nanoholes pattern is better than nanocolumns pattern in square array; but in the hexagonal array, the nanocolumns pattern is better than nanoholes pattern.

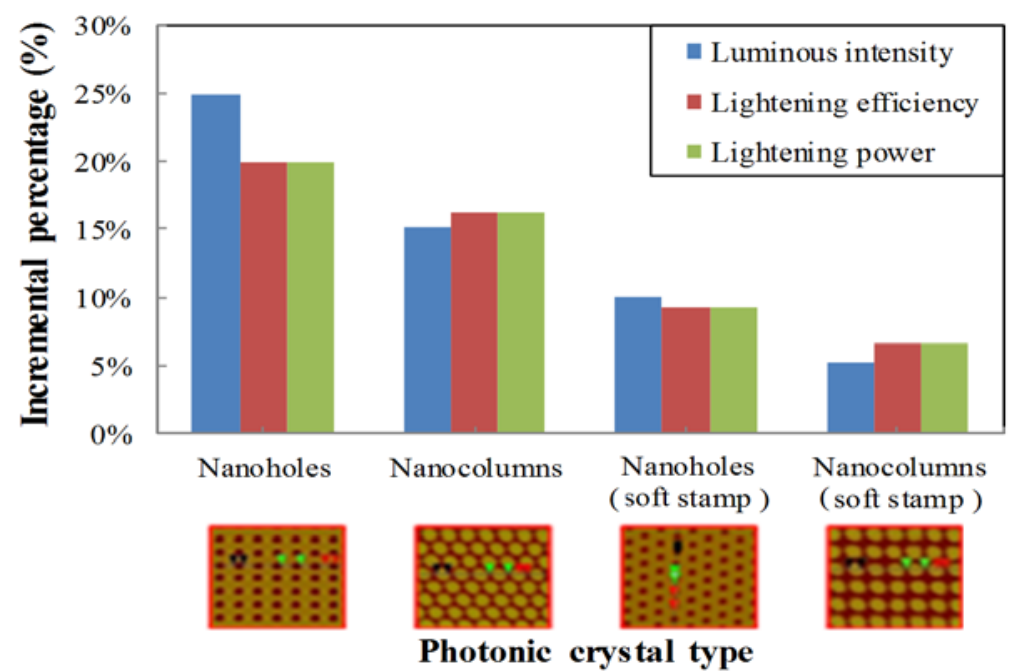

Fig. 12. Incremental percentage of different photonic crystal types.

\section{Acknowledgements}

The authors would like to acknowledge to National Science Council, Taiwan for their financial support under the contract No. NSC 98-2221-E-151-015-.

\section{References}

1. J. J. Shiang, and A. R. Duggal, Application of radiative transport theory to light extraction from organic light emitting diodes, J. Appl. Phys. 95, 2004, 2880-2888.

2. S. Mo"ller, and S. R. Forrest, Improved light out-coupling in organic light emitting diodes employing ordered microlens arrays, J. Appl. Phys. 91, 2002, 3324-3327.

3. H. J. Peng, Y. L. Ho, X. J. Yu, and H. S. Kwok, Enhanced coupling of light from organic light emitting diodes using nanoporous films, J. Appl. Phys. 96, 2004, 1649-1654.

4. Y. J. Lee, S. H. Kim, J. Huh, G. H. Kim, Y. H. Lee, S. H. Cho, Y. C. Kim, and Y. R. Do, A high- extraction- efficiency nanopatterned organic light-emitting diode, J. Appl. Lett. $82,2003,3779-3781$. 
5. Y. J. Lee, S. H. Kim, J. Huh, G. H. Kim, Y. H. Lee, S. H. Cho, Y. C. Kim, and Y. R. Do, Enhanced Light Extraction from Organic Light-Emitting Diodes with 2D SiO2/SiNx Photonic Crystals, adv. Mater. 15, 2003, 1214-1218.

6. S. Scheerlinck, D. V. Thourhout, and R. Baets, Nano Imprint Lithography for Photonic Structure Patterning, Proceedings Symposium IEEE/LEOS Benelux Chapter, 2005, 63-66.

7. F. Li, X. Li, J. Zhang, and B. Yang, Enhanced light extraction from organic light-emitting devices by using microcontact printed silica colloidal crystals, Org. Electron. 8, 2007, 635-639.

8. P. R. Krauss, P. J. Renstrom, and S. Y. Chou, Fabrication of Nanodevices Using Sub-25 nm Imprint Lithography, Device Research Conf. 1996, 194-195.

9. Y. Xia, and G. M. Whitesides, Soft Lithography, Annu. Rev. Mater. Sci. 28, 1998, 153 84.

10. X. Cheng, and L. J. Guo, A combined-nanoimprint -and-photolithography patterning technique, Microelectron. Eng. 71, 2004, 277-282.

11. X. Cheng, and L. J. Guo, One-step lithography for various size patterns with a hybrid mask-mold, Microelectron. Eng. 71, 2004, 288-293.

12. S. Y. Chou, C. Keimel, and J. Gu, Ultrafast and direct imprint of nanostructures in silicon, NATURE | 417, 2002, 835-837.

13. X. D. Huang, L. R. Bao, X. Cheng, L. J. Guo, and S. W. Pang, A. F. Yee, Reversal imprinting by transferring polymer from mold to substrate, J. Vac. Sci. Technol. B 20, 2002, 2872-2876. 